\title{
Genetic and Nongenetic Determinants of Variable Warfarin Dose Requirements: A Report from North India
}

\author{
Navjot Kaura,b Avaneesh Pandey ${ }^{c}$ Nusrat Shafiq ${ }^{c} \quad$ Ankur Gupta ${ }^{d}$ Reena Das ${ }^{\mathrm{e}}$ \\ Harkant Singh ${ }^{f}$ Jasmina Ahluwalia ${ }^{e}$ Samir Malhotra ${ }^{c}$ \\ aDepartment of Pharmacology, VMMC \& Safdarjung Hospital, New Delhi, India; ${ }^{b}$ Clinical Pharmacology Resident, \\ Department of Pharmacology, Post Graduate Institute of Medical Education and Research (PGIMER), Chandigarh, \\ India; 'Department of Pharmacology, Post Graduate Institute of Medical Education and Research (PGIMER), \\ Chandigarh, India; ${ }^{d}$ Department of Cardiology, Post Graduate Institute of Medical Education and Research \\ (PGIMER), Chandigarh, India; 'Department of Hematology, Post Graduate Institute of Medical Education and \\ Research (PGIMER), Chandigarh, India; fDepartment of CTVS, Post Graduate Institute of Medical Education and \\ Research (PGIMER), Chandigarh, India
}

\section{Keywords}

Genetic polymorphisms - Warfarin - Coumarin · Precision medicine $\cdot$ Dose optimization

\begin{abstract}
Introduction: Warfarin is widely used and will continue to be prescribed especially in developing countries due to its low cost. Given the huge patient load requiring anticoagulation, there is a need to develop strategies to optimize warfarin therapy for ensuring safe and effective anticoagulation. In the present work, we aimed at elucidating the association of genetic and nongenetic variables with warfarin dose requirement in patients attending the cardiovascular clinic in a tertiary care center of North India. Methods: This was a prospective study conducted over 1 year. Patient demographic and clinical details were captured in customized case record forms. Genotyping was done using the polymerase chain reaction-restriction fragment length polymorphism method. Pharmacogenetic influence of CYP2C9 (rs1799853 and rs1057910) and VKORC1 (rs9923231) variant alleles was studied. The association of genetic and nongenetic factors with
\end{abstract}

warfarin dose was quantified using a stepwise multivariate linear regression model. Results: Two hundred and forty patients were screened. Data from 82 eligible patients were used for quantifying the association of genetic and nongenetic factors with warfarin dose. A descriptive model based on CYP2C9*3 (rs1057910) and VKORC1 (rs9923231) variant alleles and BMI was developed. The model explains nearly half of the interindividual variation in warfarin dose requirement. Conclusion: The model explains nearly half of the interindividual variation in warfarin dose in patients with atrial fibrillation and or requiring valve replacement.

(C) 2021 S. Karger AG, Basel

\section{Introduction}

Warfarin represents the standard of care oral vitamin $\mathrm{K}$ antagonist for over 6 decades and still is widely used for prophylaxis and treatment of thromboembolic disorders across the globe $[1,2]$. Recent introduction of direct oral anticoagulants (DOACs) has expanded the choice for oral anticoagulants; yet, their clinical use remains limited. In 
India, clinicians still prefer using warfarin (coumarin derivative) over DOACs although no estimates on market share of DOACs have been published so far $[3,4]$. Not only that, warfarin will continue to be widely used in the developing world on account of low cost, ease of administration, wide market availability, and vast clinical experience in use of the drug. Furthermore, warfarin continues to be the anticoagulant of choice for many conditions where DOACs are contraindicated. These include anticoagulation in children and in those with mechanical heart valves, valvular atrial fibrillation, and renal impairment [5].

Although effective, well-known limitations to safe use of warfarin include narrow therapeutic index, large interindividual variation in drug response, and potential for numerous drug-drug and drug-food interactions [6-8]. Due to these reasons, individualization of dose is an important aspect of warfarin anticoagulation. Subtherapeutic doses put the patient at risk of thromboembolic events, whereas supratherapeutic dosing leads to high risk of bleeding complications. Finding the right dose of warfarin for an individual patient still remains a challenging task. Several studies have delineated factors that drive the interindividual variation in drug response. These include age, gender, weight, height, BMI, diet, liver function, and polymorphisms in many genes such as CYP2C9, VKORC1, CYP4F2, and GGCX [9-12].

Dosing algorithms based on these factors have been found useful for optimization of anticoagulation. Benefits of genotype-guided warfarin therapy range from shorter time to therapeutic INR and increased percentage of time in therapeutic range to reducing the occurrence of serious bleeding events [13-15]. However, these dosing algorithms have limited applicability for populations outside the ones used for development of the algorithm [16-18]. This has been attributed to a wide variation in frequency of warfarin-sensitive alleles and presence of race-specific variants influencing drug response [19]. Genotype frequencies affecting warfarin response in Indians are different from other Asian populations [20]. Furthermore, there is significant variation in frequency of warfarin-sensitive variant alleles among various regions within India [20,21]. Most of the studies conducted in India are limited to describing the frequency of variant alleles [21-25]. Very few studies have described the association of variant alleles with warfarin dose [26-29]. Hence, in the present study, we aimed at quantifying the association of genetic and nongenetic variables with warfarin dose.

Determinants of Variable Warfarin Dose

Requirements

\section{Patients and Methods}

A prospective study was conducted over a period of 1 year in the Department of Pharmacology in collaboration with Cardiology and Cardiothoracic Vascular Surgery (CTVS) Outpatient Departments of our tertiary care hospital. The study was initiated after getting approval from the Institute Ethics Committee. Consecutive patients were screened for potential eligibility in the study after obtaining written informed consent.

Adult patients of either sex suffering from atrial fibrillation and or those requiring heart valve repair/replacement surgeries on stable anticoagulation with warfarin were included. Patients with transient atrial fibrillation; with underlying hepatic (defined as elevation in alanine/aspartate transaminase $>2.5$ times the upper limit of normal) and or severe renal insufficiency (defined as creatinine clearance of $<30 \mathrm{~mL} / \mathrm{min}$ ); patients with known contraindications to anticoagulant therapy; pregnant and nursing women; and those who were unwilling to participate were excluded. Eligible patients were recruited. The study was registered in the Clinical Trial Registry of India (CTRI/2018/06/014614).

Following enrollment, patient demographic and clinical details such as age, sex, height, weight, smoking and alcohol status, indication, warfarin dose, and use of concomitant cardiac medications were captured. Stable anticoagulation was defined as having 2 INR readings in the therapeutic range (2.0-3.0) over a period of 3 months taken at least 1 week apart with no adjustment of warfarin dose. The warfarin dose in the period of stable anticoagulation was considered as stable dose for the patient. Adverse events such as bleeding and thromboembolic events or hospitalization as a result of these events were also recorded.

For genotype evaluation with regard to presence of variant alleles in CYP2C9 (CYP2C9*2; rs1799853, CYP2C9*3; rs1057910) and VKORC1 ( $-1639 G>A$; rs9923231) genes, the PCR-RFLP method was used [30]. Single venous blood sample $(6 \mathrm{~mL})$ was obtained from the patients. Blood was collected in an EDTA vial and was stored in a deep freezer at $-40^{\circ} \mathrm{C}$ until further processing. DNA was extracted using the commercial genomic DNA extraction kit (QIAGEN amp DNA mini kit). Polymerase chain reaction (PCR) was done to amplify CYP2C9 and VKORC1 regions of the genome. This was done from $100 \mathrm{ng}$ genomic DNA in a total reaction volume of $25 \mu \mathrm{L}$. Reaction mixture consisted of $2.5 \mu \mathrm{L}$ of $10 \times$ buffer, $1.5 \mu \mathrm{L}$ of $25 \mathrm{mM}$ of $\mathrm{MgCl}_{2}, 1 \mu \mathrm{L}$ of $10 \mathrm{mM}$ dNTP mix, $1 \mu \mathrm{L}$ of $10 \mathrm{mM}$ of forward and reverse primers of the CYP2C9 gene, and $1 \mu \mathrm{L}$ of $1 \mathrm{U} / \mu \mathrm{L}$ of Taq DNA polymerase. In case of $V K O R C 1$ gene amplification, optimal primer concentration was $0.3 \mu \mathrm{L}$ of $10 \mathrm{mM}$ of forward and reverse primers each. Nuclease-free water was added to make the final reaction volume to $25 \mu \mathrm{L}$. Primers and PCR conditions for gene amplification are presented in Table 1. Amplification of candidate genes was confirmed by electrophoresis of PCR products on $2 \%$ agarose gel at $120 \mathrm{~V}$ for $60 \mathrm{~min}$ stained with $0.5 \mu \mathrm{g} / \mathrm{mL}$ ethidium bromide in Tris borate EDTA buffer $\mathrm{pH} 8.0$ and visualization using a gel documentation system. The amplicon sizes for CYP2C9*2, CYP2C9*3, and VKORC1 were 690 bp, 166 bp, and 636 base pairs, respectively. PCR products were kept for overnight incubation at $37^{\circ} \mathrm{C}$ in an appropriate reaction mixture for restriction digestion. Digestion mixture comprised $10 \mu \mathrm{L}$ of the PCR product with $10 \mu \mathrm{L}$ of respective restriction endonuclease in appropriate buffer. The restriction enzymes used for digestion and restriction fragments so generated with their interpretation are presented in Table 2. Representative gel pictures are shown in Figure 1a-c. 
Table 1. Forward and reverse primers and PCR protocol

\begin{tabular}{|c|c|c|}
\hline Gene polymorphism & Primers & PCR protocol \\
\hline CYP2C9*2 (rs1799853) & $\begin{array}{l}\mathrm{F}: \text { 5'TACAAATACAATGAAAATATCATG-3' }^{\prime} \\
\mathrm{R}: \text { 5'CTAACAACCAGACTCATAATG-3' }^{\prime}\end{array}$ & $\begin{array}{l}\text { Initial denaturation: } 94^{\circ} \mathrm{C} \text { for } 5 \mathrm{~min} ; 94^{\circ} \mathrm{C} \text { for } 30 \mathrm{~s} ; 55^{\circ} \mathrm{C} \text { for } 30 \mathrm{~s} ; 72^{\circ} \mathrm{C} \text { for } \\
2 \mathrm{~min} \text {, terminal extension at } 72^{\circ} \mathrm{C} \text { for } 10 \mathrm{~min}\end{array}$ \\
\hline CYP2C9*3 (rs1057910) & $\begin{array}{l}\text { F:5AATAATAATATGCACGAGGTCCAGAGGTAC-3' } \\
\text { R:5'GATACTATGAATTTGGGACTTC-3' }\end{array}$ & $\begin{array}{l}\text { Initial denaturation: } 95^{\circ} \mathrm{C} \text { for } 3 \mathrm{~min} ; 95^{\circ} \mathrm{C} \text { for } 1 \mathrm{~min} ; 60^{\circ} \mathrm{C} \text { for } 1 \mathrm{~min} ; 72^{\circ} \mathrm{C} \\
\text { for } 1 \mathrm{~min} \text {; terminal extension at } 72^{\circ} \mathrm{C} \text { for } 10 \mathrm{~min}\end{array}$ \\
\hline VKORC1 -1639G>A (rs9923231) & $\begin{array}{l}\mathrm{F}: 5^{\prime} \text { ATCCCTCTGGGAAGTCAAGC-3' } \\
\text { R: 5'CACCTTCAACCTCTCCATCC-3' }\end{array}$ & $\begin{array}{l}\text { Initial denaturation: } 95^{\circ} \mathrm{C} \text { for } 3 \mathrm{~min} ; 95^{\circ} \mathrm{C} \text { for } 30 \mathrm{~s} ; 55^{\circ} \mathrm{C} \text { for } 1 \mathrm{~min} ; 72^{\circ} \mathrm{C} \\
\text { for } 1 \mathrm{~min} 30 \mathrm{~s} \text {; terminal extension at } 72^{\circ} \mathrm{C} \text { for } 10 \mathrm{~min}\end{array}$ \\
\hline
\end{tabular}

Table 2. Restriction enzymes and digested product sizes (in base pairs)

\begin{tabular}{llll}
\hline Gene & PCR product size, bp & Restriction enzyme & Digested product size, bp \\
\hline CYP2C9*2 & $690 \mathrm{bp}$ & Avall & WT:521 bp, $169 \mathrm{bp} ; \mathrm{Htz:} 690 \mathrm{bp}, 521 \mathrm{bp}, 169 \mathrm{bp} ;$ Mut: $690 \mathrm{bp}$ \\
CYP2C9*3 & $166 \mathrm{bp}$ & Kpnl & WT: $166 \mathrm{bp} ; \mathrm{Htz}: 166 \mathrm{bp}, 136 \mathrm{bp}, 30 \mathrm{bp}$; Mut: $136 \mathrm{bp}, 30 \mathrm{bp}$ \\
VKORC1 $-1639 G>A$ & $636 \mathrm{bp}$ & Nsil & WT:472 bp,114bp,50 bp; Htz:522 bp,472 bp, 114 bp,50 bp \\
& & Mut: $522 \mathrm{bp}, 114 \mathrm{bp}$ \\
\hline
\end{tabular}

bp, base pairs; WT, wild type; Htz, heterozygous mutant; Mut, homozygous mutant.

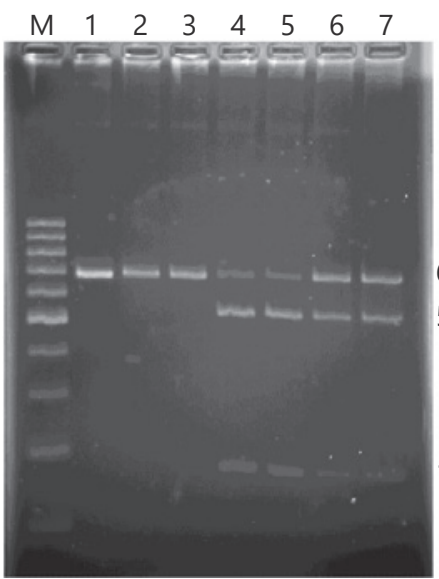

a

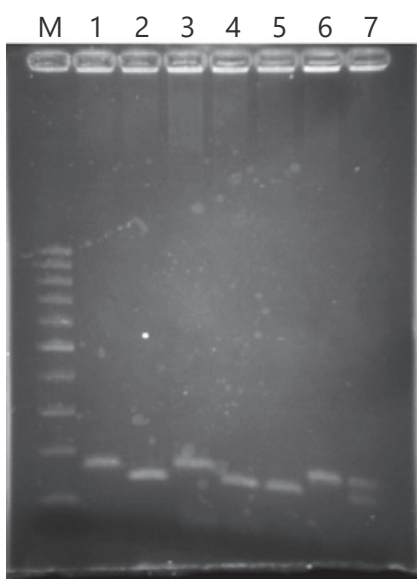

b

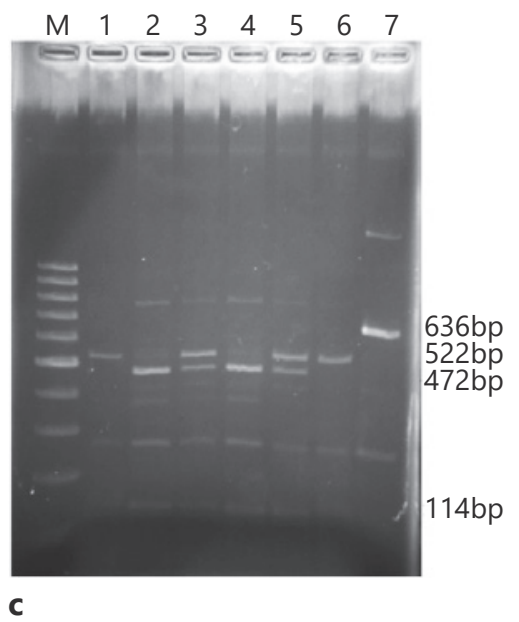

(166 bp and $136 \mathrm{bp}$ ). Note that the 30 -base pair product is not visible. c $2.5 \%$ agarose gel pattern of VKORC1 $-1639 G>A$. * Lanes 1 and 6 show the homozygous mutant genotype AA (522 bp, $114 \mathrm{bp}$, and $50 \mathrm{bp}$ ), lanes 2 and 4 show the wild homozygous (GG) genotype (472 bp, $114 \mathrm{bp}$, and $50 \mathrm{bp}$ ), lanes 3 and 5 show heterozygous AG genotype, and lane 7 shows the undigested (U) VKORC1gene PCR product ( $636 \mathrm{bp}$ ). Note that the 50 -base pair product is not visible. 
Fig. 2. Flow of participants during the

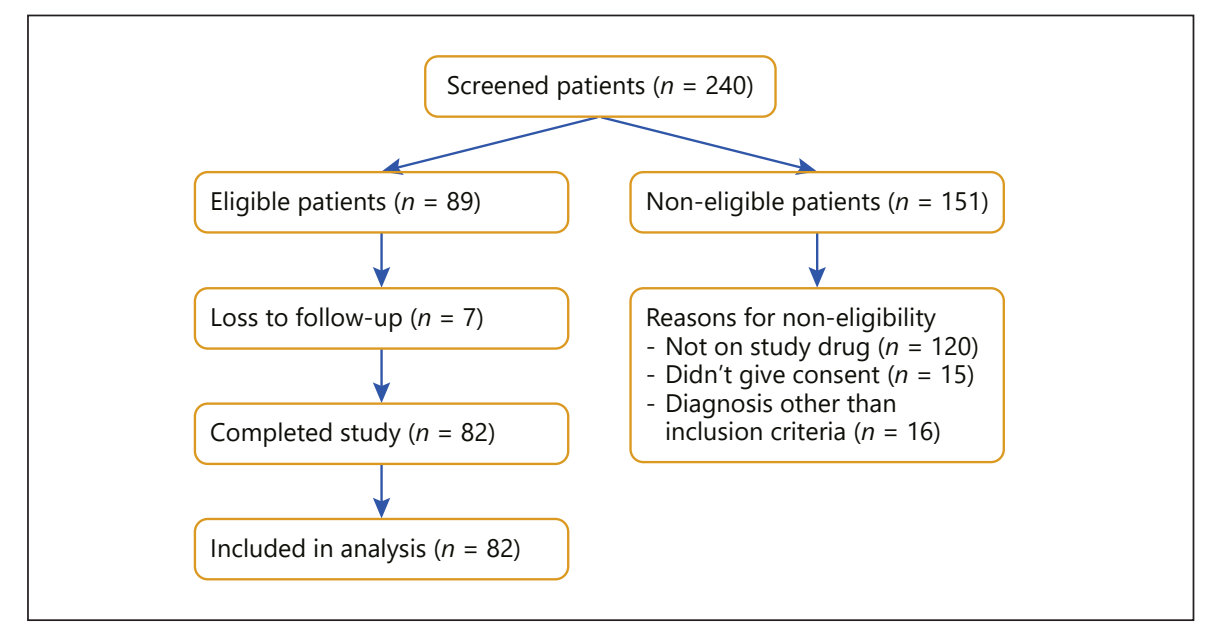
study period.

\section{Statistical Analysis}

A sample size of 80 gives a probability of $>99 \%$ for detecting all alleles in the 3 genes under study, that is, VKORC1, CYP2C9*2, and CYP2C9*3 assuming $80-90 \%$ frequency of the wild type and about $5-10 \%$ frequency of the other variants [31]. Descriptive statistics were used for continuous (mean $\pm \mathrm{SD}$, or median [range]) variables. Categorical data were presented as frequencies or percentages. The Kolmogorov-Smirnov test was used for assessing the normality of data. Log transformation was done to normalize the distribution of the warfarin dose. Comparison of mean stable warfarin dose across different genotypes was done using 1-way analysis of variance followed by the post hoc Scheffe test. Stepwise multiple linear regression analysis was undertaken to model the relationship of warfarin dose per week with the clinical and pharmacogenetic variables. $p$ value $<0.05$ was considered statistically significant. All analyses were done using SPSS version 22.

\section{Results}

A total of 240 patients were screened over a period of 1 year with consequent enrollment of 89 eligible patients. The analysis dataset includes data from 82 patients who completed the study and had no missing data on any of the study variables (shown in Fig. 2). The majority (86.5\%) of the participants received warfarin for atrial fibrillation. Other demographic and clinical details including genotype frequencies with $95 \%$ confidence intervals are presented in Table 3. Mean $( \pm$ SD) stable warfarin dose was $28.82( \pm 12.59) \mathrm{mg} /$ week with an interquartile range of 14 $\mathrm{mg} /$ week. Stable warfarin dose in the study cohort ranged from $5 \mathrm{mg} /$ week to $77 \mathrm{mg} /$ week. This represents over 15fold variation in warfarin dose requirement among patients. Further CYP2C9 haplotypes were constructed based on combined individual CYP2C $9^{*} 2$ and $C Y P 2 C 9^{*} 3$ genotypes. The frequency distribution of study subjects based on CYP2C9 haplotypes and VKORC1 genotype is summarized in Table 4.

\section{Comparison of Warfarin Dose Response across Different} Genotypes

Comparison of mean $( \pm S D)$ stable warfarin doses across $C Y P 2 C 9^{*} 2$ genotypes revealed a dose requirement of $29.18 \pm 12.76 \mathrm{mg} /$ week in individuals with the wild genotype, followed by $27.13 \pm 11.35 \mathrm{mg} /$ week in heterozygous and $16 \mathrm{mg} /$ week in 1 patient with homozygous mutant genotype. Although there was trend to decreased requirement of warfarin with increasing number of variant $C Y P 2 C 9^{*} 2$ alleles, the difference did not reach statistical significance $(p=0.543)$. Similarly, across CYP2C $9^{*} 3$ genotypes, we observed the highest dose requirement of 30.9 $\pm 12.30 \mathrm{mg} /$ week in the wild genotype followed by 24.08 $\pm 9.25 \mathrm{mg} /$ week in heterozygous and the lowest dose requirement of $9.50 \pm 3.69 \mathrm{mg} /$ week in homozygous $\mathrm{mu}-$ tants $(p=0.001)$. To study the effect of CYP2C $9^{*} 2$ and CYP2C $9 * 3$ allelic variation in combination, we compared warfarin dose requirements in individuals with different haplotypes of the CYP2C9 gene (Fig. 3). The difference was found to be statistically significant $(p=$ 0.002 ).

Significant variation was also noted for warfarin dose requirement across different genotypes for the VKORC1 gene $(p=0.02)$. Mean $( \pm \mathrm{SD})$ weekly warfarin dose requirement was $31 \pm 13.03 \mathrm{mg} /$ week followed by $23.52 \pm$ 9.76 and $18.50 \pm 3.53 \mathrm{mg} /$ week in individuals with wild, heterozygous, and homozygous mutant genotypes, respectively. Combined effect of warfarin-sensitive variant alleles in both VKORC1 and CYP2C9 genes on warfarin dose is shown in Figure 4. Adverse event of minor bleeding occurred in 2 patients during the study period. 
Table 3. Demographic, clinical, and genotype characteristics of the study cohort

\begin{tabular}{|c|c|}
\hline Patients, $N$ & 82 \\
\hline Age, mean $\pm S D$, years & $53.4 \pm 13.38$ \\
\hline Females & $50.8 \pm 11.07$ \\
\hline Males & $57.4 \pm 15.88$ \\
\hline \multicolumn{2}{|l|}{ Gender, $n(\%)$} \\
\hline Male & $33(40)$ \\
\hline Female & $49(60)$ \\
\hline Height, mean $\pm S D, c m$ & $160.9 \pm 11.24$ \\
\hline Weight, mean $\pm S D, k g$ & $63.4 \pm 14.70$ \\
\hline \multicolumn{2}{|l|}{ Body mass index, $n(\%), \mathrm{kg} / \mathrm{m}^{2}$} \\
\hline$<18.5$ & $8(9.8)$ \\
\hline $18.5-24.9$ & $39(47.6)$ \\
\hline $24.91-29.9$ & $24(29.3)$ \\
\hline$\geq 29.9$ & $11(13.4)$ \\
\hline \multicolumn{2}{|c|}{ Indication for warfarin use, $n$ (\%) } \\
\hline Atrial fibrillation & $71(86.5)$ \\
\hline Valve replacement & $11(13.5)$ \\
\hline \multicolumn{2}{|l|}{ Smoking status, $n(\%)$} \\
\hline Yes & $1(1.2)$ \\
\hline No & $81(98.7)$ \\
\hline \multicolumn{2}{|l|}{ Alcohol status, $n(\%)$} \\
\hline Yes & $7(8.54)$ \\
\hline No & 75 (91.4) \\
\hline \multicolumn{2}{|c|}{ Mean stable warfarin dose, mg/week } \\
\hline Mean \pm SD & $28.82 \pm 12.59$ \\
\hline Median (range) & $28(5-77)$ \\
\hline \multicolumn{2}{|l|}{ Concomitant medications, $n(\%)$} \\
\hline Diuretics & $69(84)$ \\
\hline Beta blockers & $61(74.39)$ \\
\hline Calcium channel blocker & $26(32)$ \\
\hline Digoxin & $21(25.6)$ \\
\hline Antihypertensives & $20(24.4)$ \\
\hline Statins & $17(21)$ \\
\hline Low-dose aspirin & $16(20.9)$ \\
\hline Amiodarone & $04(4.9)$ \\
\hline \multicolumn{2}{|c|}{ Genotype frequencies; $n(\%) ;[95 \% \mathrm{Cl}]$} \\
\hline \multicolumn{2}{|l|}{ CYP2C9*2 } \\
\hline CC (wild type) & 73 (89.02); [80.43-94.11] \\
\hline $\mathrm{CT}$ & 08 (9.76); [5.03-18.09] \\
\hline$\pi$ & 01 (1.22); [0.22-6.59] \\
\hline \multicolumn{2}{|l|}{ CYP2C9*3 } \\
\hline AA (wild type) & 65 (79.26); [69.29-86.63] \\
\hline$A C$ & $13(15.85) ;[9.5-25.25]$ \\
\hline CC & 04 (4.87); [ 1.91-11.88] \\
\hline \multicolumn{2}{|l|}{ VKORC1 $1639 G>A$} \\
\hline GG (wild type) & 57 (69.51); [58.86-78.41] \\
\hline GA & 23 (28.04); [19.48-38.59] \\
\hline$A A$ & $02(2.44) ;[0.67-8.46]$ \\
\hline
\end{tabular}

\section{Modeling the Warfarin Dose Requirement}

Stepwise multiple linear regression analysis was undertaken to model and quantify the association of genetic and nongenetic factors with weekly warfarin dose requirement. To avoid overfitting of data, 5 pertinent can-
Table 4. Frequency distribution of study participants with regard to CYP2C9 haplotypes and VKORC1 genotype

\begin{tabular}{llllll}
\hline VKORC1 & \multicolumn{5}{l}{ CYP2C9 haplotypes } \\
\cline { 2 - 6 } & $* 1 / * 1$ & $* 1 / * 2$ & $* 1 / * 3$ & $* 2 / * 2$ & $* 3 / * 3$ \\
\hline GG & 37 & 06 & 11 & - & 03 \\
AG & 19 & 01 & 01 & 01 & 01 \\
AA & 01 & 01 & - & - & - \\
\hline
\end{tabular}

didate variables were considered, that is, age, gender, BMI, CYP2C9*3, and VKORC1 $(-1639 G>A)$ variant alleles. The multivariate regression model identified $C Y$ P2C9*3, VKORC1, and BMI as significant determinants of warfarin dose. The model explains $47.5 \%$ of interindividual variability in warfarin dose (Table 5 ). Based on the model (Table 6), the weekly warfarin dose requirement can be represented as

Log warfarin dose $(\mathrm{mg} /$ week $)=1.682-$ $0.247\left(\right.$ CYP2C $\left.^{*} 3\right)-0.152($ VKORC1 $)+0.010 \times$ BMI.

\section{Discussion}

In the present work, we aimed at quantifying the association of genetic and nongenetic factors with the warfarin dose requirements in cardiac outpatients attending North Indian tertiary care hospital. Genotype frequencies for both CYP2C9 and VKORC1 genes reported here are in agreement with previous reports [20-22].

We found over 15 -fold variation in warfarin dose requirement among the studied cohort. Individuals carrying warfarin-sensitive variant alleles for CYP2C9*3 and $V K O R C 1$ required significantly lower warfarin doses compared to individuals with the wild genotype. We observed a trend of decreasing warfarin dose in patients carrying CYP2C9*2 variant alleles as well, but the difference was not statistically significant. The presence of variant alleles in both CYP2C9 and VKORC1 genes showed additive effect on decreasing warfarin doses. For instance, 1 patient with the $* 3 / * 3$ haplotype of $C Y$ P2C9 with the AG genotype for VKORC1 required the lowest dose of $5 \mathrm{mg} /$ week among the studied cohort. In contrast, an individual with only the $* 3 / * 3$ haplotype with the wild genotype for the VKORC1 gene had a higher dose requirement of $11 \mathrm{mg} /$ week. Similarly, presence of the AG genotype along with the *1/*2 haplotype decreased warfarin dose requirements from 
Fig. 3. Distribution of weekly warfarin dose

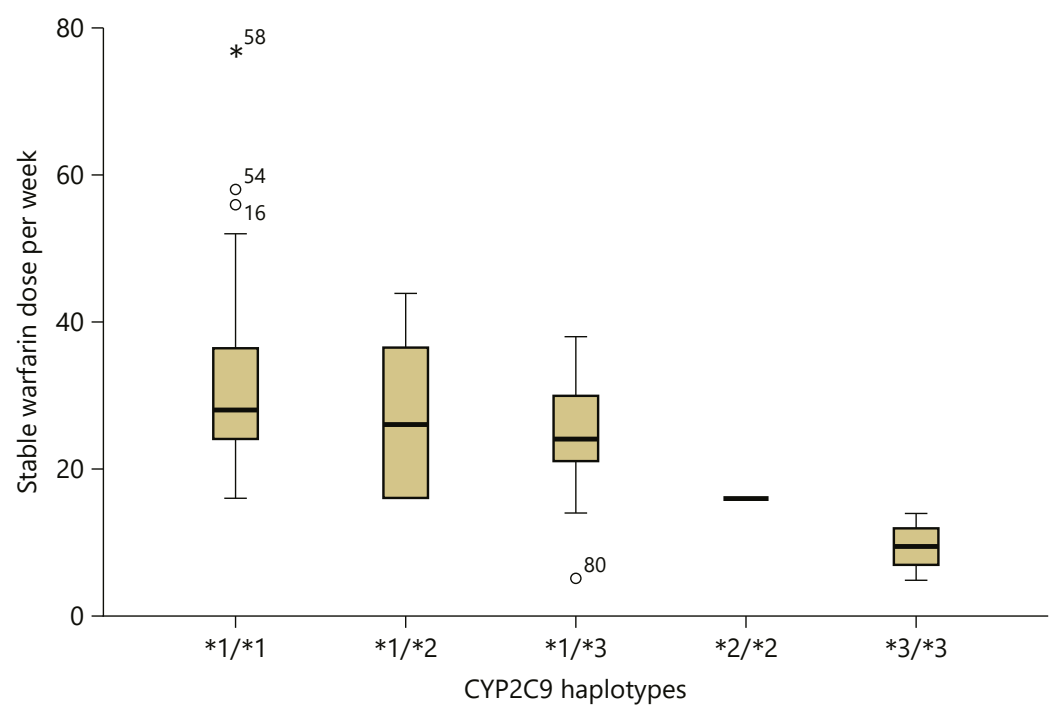
across CYP2C9 haplotypes.

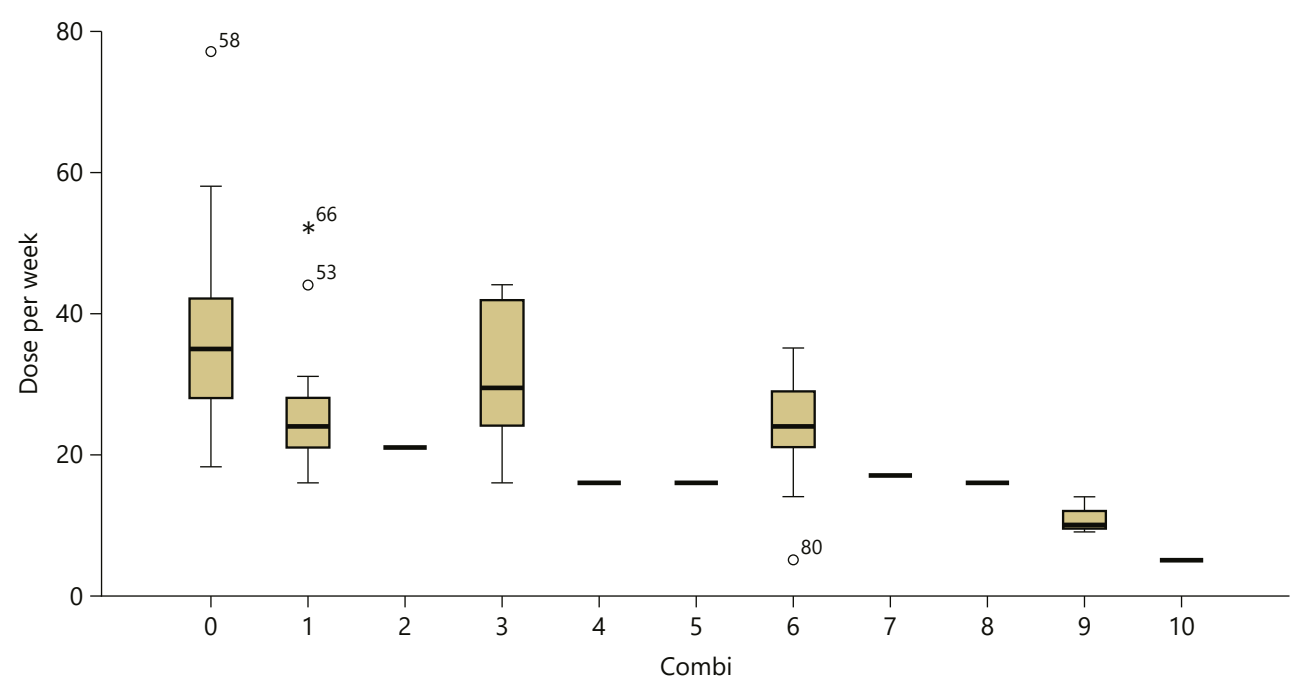

Fig. 4. Distribution of weekly warfarin dose in the study cohort based on genotypes for both CYP2C9 and VKORC1*. ${ }^{*}$ Codes refer to the following combination of CYP2C9 haplotypes and VKORC1 genotype: $0 \rightarrow\left({ }^{*} 1 /{ }^{*} 1\right.$ CYP2C9 haplotype + GG genotype of VKORC1); $1 \rightarrow\left({ }^{*} 1 /{ }^{*} 1\right.$ CYP2C9 haplotype + AG genotype of VKORC1); $2 \rightarrow$ $\left({ }^{*} 1 /{ }^{*} 1\right.$ CYP2C9 haplotype + AA genotype of VKORC1); $3 \rightarrow\left({ }^{*} 1 / *^{*}\right.$ CYP2C9 haplotype + GG genotype of VKORC1); $4 \rightarrow(* 1 / * 2 \mathrm{CY}-$

$30.83 \pm 10.7 \mathrm{mg} /$ week to $16 \mathrm{mg} /$ week compared to $* 1 /{ }^{*} 2$ haplotype individuals possessing wild-type VKORC1alleles. Two patients with minor bleeding also had variant alleles in both CYP2C9 and VKORC1 genes. Studies have pointed to more chances of out of range INR and
P2C9 haplotype + AG genotype of VKORC1);5 $\rightarrow(* 1 / * 2$ CYP2C9 haplotype + AA genotype of VKORC1); $6 \rightarrow(* 1 / * 3$ CYP2C9 haplotype + GG genotype of VKORC1); $7 \rightarrow\left(* 1 /{ }^{*} 3\right.$ CYP2C9 haplotype + AG genotype of VKORC1 $) ; 8 \rightarrow(* 2 / * 2$ CYP2C 9 haplotype + AG genotype of VKORC1); $9 \rightarrow(* 3 / * 3$ CYP2C9 haplotype + GG genotype of VKORC1); $10 \rightarrow(* 3 / * 3$ CYP2C9 haplotype + AG genotype of VKORC1).

more bleeding events in individuals with variant alleles $[32,33]$.

The stepwise multivariate regression model identified CYP2C $9 * 3, V K O R C 1-1639 G>A$, and BMI as significant determinants of warfarin dose. Together, these factors ex- 
Table 5. Stepwise multiple linear regression model

\begin{tabular}{lllll}
\hline \multicolumn{3}{l}{ Model summary } & & \\
model & $R$ & $R^{2}$ & adjusted $R^{2}$ & std. error of the estimate \\
\hline 1 & $0.547^{\mathrm{a}}$ & 0.299 & 0.290 & 0.17477 \\
2 & $0.663^{\mathrm{b}}$ & 0.440 & 0.425 & 0.15721 \\
3 & $0.703^{\mathrm{c}}$ & 0.494 & 0.475 & 0.15030 \\
\hline
\end{tabular}

a Predictors: (constant), CYP2C9*3. b Predictors: (constant), CYP2C9*3 and VKORC1. ' Predictors: (constant), CYP2C9*3, VKORC1, and BMI.

plain nearly half of the interindividual variation in warfarin dose requirement. The model showed genetic factors to be more important sources of variability in warfarin dose response compared to clinical factors. These findings are in conformity with previous research reports $[10-12,27]$. CYP $2 C 9^{*} 3$ polymorphism alone accounted for $29 \%$ of variation in dose response and can be seen as large compared to other studies. In contrast to other studies, which identified CYP2C9*2 as another important factor for varying warfarin doses, we did not find the association of the CYP2C9*2 gene with warfarin dose as significant, although trend to decreasing warfarin dose was observed [27, 29, 34]. Compared to other studies, the effect of BMI in our model was modest $(\beta=0.010)$. One of the plausible reasons for this could be the absence of morbidly obese patients in our study cohort. A recent study $(n=831)$ showed that mean weekly warfarin dose increases by a factor of 0.69 for a unit increase in BMI. The large impact of BMI on warfarin doses in this study was likely due to inclusion of patients over a wide BMI range of $13.4-63.1 \mathrm{~kg} / \mathrm{m}^{2}$. They included about 49 morbidly obese $\left(\mathrm{BMI}>40 \mathrm{~kg} / \mathrm{m}^{2}\right)$ patients in the analysis. Moreover, they studied the effect of BMI on warfarin dose in isolation [35]. The impact of smoking and alcohol on warfarin dose requirement is unclear from the present study due to very limited representation of smokers $(n=$ 1) and occasional alcoholics $(n=7)$.

Strengths of the study: the study quantifies the association of genetic and nongenetic factors with warfarin dose in a homogenous cohort of cardiac patients on warfarin. This may be of significance in view of a recent randomized trial showing greater benefit of genotype-guided warfarin dosing in patients of atrial fibrillation compared to patients with pulmonary embolism and deep vein thrombosis [36].

Limitations of the study: limitations of our work include small sample size and studying a limited number of
Table 6. Regression model used to model warfarin dose requirement

\begin{tabular}{|c|c|c|c|c|c|}
\hline \multicolumn{6}{|l|}{ Coefficients $^{\mathrm{a}}$} \\
\hline \multirow[t]{2}{*}{ model } & \multicolumn{2}{|c|}{$\begin{array}{l}\text { unstandardized } \\
\text { coefficients }\end{array}$} & \multirow{2}{*}{$\begin{array}{l}\text { standardized } \\
\text { coefficients } \\
\text { beta }\end{array}$} & \multirow[t]{2}{*}{$T$} & \multirow[t]{2}{*}{ sig } \\
\hline & B & std. error & & & \\
\hline 1 (constant) & 1.680 & 0.049 & & 34.176 & 0.000 \\
\hline CYP2C9*3 & -0.212 & 0.036 & -0.547 & -5.839 & 0.000 \\
\hline 2 (constant) & 1.910 & 0.068 & & 28.119 & 0.000 \\
\hline CYP2C9*3 & -0.236 & 0.033 & -0.607 & -7.115 & 0.000 \\
\hline VKORC1 & -0.151 & 0.034 & -0.380 & -4.457 & 0.000 \\
\hline 3 (constant) & 1.682 & 0.102 & & 16.495 & 0.000 \\
\hline CYP2C9*3 & -0.247 & 0.032 & -0.637 & -7.750 & 0.000 \\
\hline VKORC1 & -0.152 & 0.032 & -0.383 & -4.695 & 0.000 \\
\hline BMI & 0.010 & 0.003 & 0.236 & 2.903 & 0.005 \\
\hline
\end{tabular}

${ }^{\text {a }}$ Dependent variable: logdose warfarin.

genetic polymorphisms. However, we accounted for the most important polymorphisms reported to affect warfarin pharmacokinetics and pharmacodynamics across the literature.

\section{Acknowledgments}

The authors would like to thank all the patients who volunteered for the study. They also extend their gratitude to Ms. Jasbir Kaur; lab technician, and Ms. Anu Aggarwal, PhD student, Department of Hematology, for contribution in method development.

\section{Statement of Ethics}

The study was conducted ethically in accordance with the principles of the Declaration of Helsinki. All the study subjects have given their written informed consent. The study protocol was approved by the Institute Ethics Committee (Intramural) at PGIMER, Chandigarh, Vide Reference No. NK/2608/DM/3107.

\section{Conflict of Interest Statement}

The authors have no conflicts of interest to declare.

\section{Funding Sources}

The work was done as a DM (Clinical Pharmacology) thesis and partly supported by departmental funding.
Public Health Genomics 2022;25:52-60 DOI: $10.1159 / 000519462$
Kaur/Pandey/Shafiq/Gupta/Das/Singh/ Ahluwalia/Malhotra 


\section{Author Contributions}

Dr. Nusrat Shafiq and Dr. Samir Malhotra conceptualized the study, monitored conduct and analysis, and critically reviewed the manuscript. Dr. Navjot Kaur and Dr. Avaneesh Pandey contributed to data collection, genotyping, data analysis, compilation of results, and drafting the manuscript. Dr. Reena Das and Dr. Jasmina Ahluwalia designed genotype experiments and contributed to genotyping data analysis and reviewing the manuscript. Dr. Ankur Gupta and Dr. Harkant Singh contributed to enrolling eligible patients, data analysis, and critical review of the manuscript.

\section{Data Availability Statement}

All data generated or analyzed during this study are included in this article. Further enquiries can be directed to the corresponding author.

\section{References}

1 Pirmohamed M. Warfarin: almost 60 years old and still causing problems. Br J Clin Pharmacol. 2006 Nov;62(5):509-11.

2 Wigle P, Hein B, Bernheisel CR. Anticoagulation: updated guidelines for outpatient management. Am Fam Physician. 2019 Oct1; 100(7):426-34.

3 Jadav S, Dumatar C. Utilization pattern of antiplatelet and anticoagulant medicines among the patients suffering from atrial fibrillation. Ijmedph. 2016;6(2):103-8.

4 Singh V, Gopinath K, Behzadpour A, Meera NK. Anticoagulant utilization evaluation in a tertiary care teaching hospital: an observational prospective study in medical in patients. Ijopp. 2015 Apr;8(2):61-6.

5 Pirmohamed M. Warfarin: the end or the end of one size fits all therapy? J Pers Med. 2018 Jun 28;8(3):22.

$6 \mathrm{Zu} \mathrm{Y,} \mathrm{Tan} \mathrm{M-H,} \mathrm{Chowbay} \mathrm{B,} \mathrm{Lee} \mathrm{SC,} \mathrm{Yap} \mathrm{H,}$ Lee MTM, et al. Nanoprobe-based genetic testing. Nano Today. 2014 Apr 30;9(2):16671.

7 Harder S, Thürmann P. Clinically important drug interactions with anticoagulants. An update. Clin Pharmacokinet. 1996 Jun;30(6): 416-44.

8 Leite PM, Martins MAP, Castilho RO. Review on mechanisms and interactions in concomitant use of herbs and warfarin therapy. Biomed Pharmacother. 2016 Oct;83:14-21.

9 Lee MT, Klein TE. Pharmacogenetics of warfarin: challenges and opportunities. J Hum Genet. 2013 Jun;58(6):334-8.

10 Wadelius M, Chen LY, Downes K, Ghori J, Hunt S, Eriksson N, et al. Common VKORC1 and GGCX polymorphisms associated with warfarin dose. Pharmacogenomics J. 2005; 5(4):262-70.

11 Aquilante CL, Langaee TY, Lopez LM, Yarandi HN, Tromberg JS, Mohuczy D, et al. Influence of coagulation factor, vitamin $\mathrm{K}$ epoxide reductase complex subunit 1 , and cytochrome P450 2C9 gene polymorphisms on warfarin dose requirements. Clin Pharmacol Ther. 2006 Apr;79(4):291-302.

12 Gage BF, Eby C, Johnson JA, Deych E, Rieder MJ, Ridker PM, et al. Use of pharmacogenetic and clinical factors to predict the therapeutic dose of warfarin. Clin Pharmacol Ther. 2006 Apr;79(4):291-302.

13 Franchini M, Mengoli C, Cruciani M, Bonfanti C, Mannucci PM. Effects on bleeding complications of pharmacogenetic testing for initial dosing of vitamin $\mathrm{K}$ antagonists: a systematic review and meta-analysis. J Thromb Haemost. 2014 Sep;12(9):1480-7.

14 Goulding R, Dawes D, Price M, Wilkie S, Dawes M. Genotype-guided drug prescribing: a systematic review and meta-analysis of randomized control trials. Br J Clin Pharmacol. 2015 Oct;80(4):868-77.

15 Tse G, Gong M, Li G, Wong SH, Wu WKK, Wong WT, et al. Genotype-guided warfarin dosing vs. conventional dosing strategies: a systematic review and meta-analysis of randomized controlled trials. Br J Clin Pharmacol. 2018 Sep;84(9):1868-82.

16 Santos PC, Marcatto LR, Duarte NE, Gadi Soares RA, Cassaro Strunz CM, Scanavacca $M$, et al. Development of a pharmacogeneticbased warfarin dosing algorithm and its performance in Brazilian patients: highlighting the importance of population-specific calibration. Pharmacogenomics. 2015 Jul;16(8): 865-76.

17 Tan SL, Li Z, Song GB, Liu LM, Zhang W, Peng J, et al. Development and comparison of a new personalized warfarin stable dose prediction algorithm in Chinese patients undergoing heart valve replacement. Pharmazie. 2012 Nov;67(11):930-7.

18 Mak M, Lam C, Pineda SJ, Lou M, Xu LY, Meeks C, et al. Pharmacogenetics of warfarin in a diverse patient population. J Cardiovasc Pharmacol Ther. 2019 Nov;24(6):52133.

19 Kaye JB, Schultz LE, Steiner HE, Kittles RA, Cavallari LH, Karnes JH. Warfarin pharmacogenomics in diverse populations. Pharmacotherapy. 2017 Sep;37(9):1150-63.

20 Giri AK, Khan NM, Grover S, Kaur I, Basu A, Tandon N, et al. Genetic epidemiology of pharmacogenetic variations in CYP2C9, CYP4F2 and VKORC1 genes associated with warfarin dosage in the Indian population. Pharmacogenomics. 2014 Jul;15(10):133754.

21 Nahar R, Deb R, Saxena R, Puri RD, Verma IC. Variability in CYP2C9 allele frequency: a pilot study of its predicted impact on warfarin response among healthy South and North Indians. Pharmacol Rep. 2013;65(1): 187-94.

22 Rathore SS, Agarwal SK, Pande S, Mittal T, Mittal B. Frequencies of VKORC1 -1639 G>
A, CYP2C9*2 and CYP2C9*3 genetic variants in the Northern Indian population. Biosci Trends. 2010 Dec;4(6):333-7.

23 Shalia KK, Doshi SM, Parikh S, Pawar PP, Divekar SS, Varma SP, et al. Prevalence of VKORC1 and CYP2C9 gene polymorphisms in Indian population and its effect on warfarin response. J Assoc Physicians India. 2012 Dec; 60:34-8.

24 Krishna Kumar D, Manjunath S, Adithan C, Shewade D, Ushakiran P, Reneega G. Inter and intra ethnic variation of vitamin $\mathrm{K}$ epoxide reductase complex and cytochrome P450 4F2 genetic polymorphisms and their prevalence in South Indian population. Indian J Hum Genet. 2013 Jul;19(3) 301-10.

25 Shukla T, Reddy SC, Korrapatti S, Munpally SK, Tripathi R, Dikshit V, et al. A novel VKORC1 promoter mutation found causing warfarin resistance, along with $-1639 \mathrm{G}>\mathrm{A}$ promoter mutation-A pilot study on the genetic variation in patients on warfarin therapy in South India. Biomarkers Genomic Med. 2013;5(4):147-56.

26 Natarajan S, Ponde CK, Rajani RM, Jijina F, Gursahani R, Dhairyawan PP, et al. Effect of CYP2C9 and VKORC1 genetic variations on warfarin dose requirements in Indian patients. Pharmacol Rep. 2013 Oct 31;65(5): 1375-82.

27 Kumar DK, Shewade DG, Loriot MA, Beaune P, Balachander J, Chandran BS, et al. Effect of CYP2C9, VKORC1, CYP4F2 and GGCX genetic variants on warfarin maintenance dose and explicating a new pharmacogenetic algorithm in South Indian population. Eur J Clin Pharmacol. 2014 Jan;70(1): 47-56.

28 Pavani A, Naushad SM, Rupasree Y, Kumar TR, Malempati AR, Pinjala RK, et al. Optimization of warfarin dose by populationspecific pharmacogenomic algorithm. Pharmacogenomics J. 2012 Aug;12(4):30611.

29 Gaikwad T, Ghosh K, Avery P, Kamali F, Shetty S. Warfarin dose model for the prediction of stable maintenance dose in Indian patients. Clin Appl Thromb Hemost. 2018 Mar; 24(2):353-9.

30 Dai S, Long Y. Genotyping analysis using an RFLP assay. Methods Mol Biol. 2015;1245: 91-9. 
31 Chandrika BR. Sample size considerations in genetic polymorphism studies. Hum Hered. 2001;52(4):191-200.

32 Aithal GP, Day CP, Kesteven PJ, Daly AK. Association of polymorphisms in the cytochrome P450 CYP2C9 with warfarin dose requirement and risk of bleeding complications. Lancet. 1999 Feb 27;353(9154):717-9.
33 Gaikwad T, Ghosh K, Kulkarni B, Kulkarni V, Ross C, Shetty S. Influence of CYP2C9 and VKORC1 gene polymorphisms on warfarin dosage, over anticoagulation and other adverse outcomes in Indian population. Eur J Pharmacol. 2013 Jun;710(1-3):80-4.

34 Limdi N, Goldstein J, Blaisdell J, Beasley T, Rivers C, Acton R. Influence of CYP2C9 genotype on warfarin dose among African American and European Americans. Per Med. 2007 May 1;4(2):157-69.
35 Mueller JA, Patel T, Halawa A, Dumitrascu A, Dawson NL. Warfarin dosing and body mass index. Ann Pharmacother. 2014 May;48(5): 584-8.

36 Makar-Aušperger K, Krželj K, Lovrić Benčić M, Radačić Aumiler M, Erdeljić Turk V, Božina N. Warfarin dosing according to the genotype-guided algorithm is most beneficial in patients with atrial fibrillation: a randomized parallel group trial. Ther Drug Monit. 2018 Jun;40(3):362-8. 